\title{
Investigation on the effect of stacking sequence on mechanical properties of a basalt and carbon fiber hybrid composite DOI:10.36909/jer.ICMMM.15803
}

\author{
Naveen $\mathrm{R}^{\mathrm{a}}$, Kumar $\mathrm{M}^{\mathrm{b} *}$, Mathan $\mathrm{A}^{\mathrm{a}}$, Dhushyanath $\mathrm{D}^{\mathrm{a}}$ \\ Department of Mechanical Engineering, Bannari Amman Institute of Technology, Erode, \\ 638401, India. \\ Department of Mechanical Engineering, KPR Institute of Engineering and Technology, \\ Coimbatore, 641407, India. \\ *Corresponding Author: kuaymar@gmail.com
}

\begin{abstract}
In the recent times, usage of Carbon Fiber Reinforced Plastics (CFRP) is inevitable in almost all the engineering sectors especially in Aerospace industries. In spite of its wide range of applications, the usage is currently limited due to its higher cost while compare to the other forms of composite. To overcome this issue, recent researches have introduced low cost high strength composite materials. The present work attempts to investigate the mechanical properties of hybrid composite made out of Carbon and Basalt fiber. The hybrid composites are fabricated through compression moulding technique with different stacking sequence of ply laminates. The fabricated laminates are then subjected to tensile, flexural, hardness and impact tests as per ASTM standard to characterize the mechanical properties. From the experimental results it is evidenced that the strength of hybrid laminates were strongly dependents on the stacking sequence of fiber reinforcement. The fabricated laminates of carbon fiber as top layer reveal improved mechanical strength than that of basalt fiber as top layer. The microstructural investigations also been done on the fabricated composites and are reported.
\end{abstract}

Keywords: Carbon fiber, Basalt fiber, Stacking sequence, Mechanical Properties 


\section{INTRODUCTION}

The polymer composites are the advanced materials in various aerospace and automotive applications. The Fiber reinforce composites (FRP) can be tailored the mechanical properties by incorporating the reinforcements and matrix but the metals can't optimized..With the help of two or more fibers by using the same matrix the mechanical properties can be varied. That's why in last two decades the studies on hybrid composites increased through the concept of fiber hybridization in order to fabricate the composites with superior properties[Sapuan et al. 2020],. The significance of composite materials are increasining day to day to mee the high mechanical performance in various sectors..

Carbon fibres are known as aids because of their overwhelming properties, e.g. high mechanical strength and flexibility module, low density and exceptional fire resistance. It makes basic carbon fibres, for example, it is using in motor vehicles, airplanes, boats, improvements, and games in broad areas of planning. However, because of the delicacy of carbon fibre, carbon fibre composites are somewhat powerless against pressure concentration. Carbon fibres also include expensive creation. The best way to deal with carbon fibre deficiency improvement is Carbon Fibred Reinforced Plastic (CFRP). The combination of the cross variety carbon fibre appeared to be the highest Flexural strength.

A composite material is a non-uniform solid developed by mixing two or more materials that are mechanical bind together. Composites generally consist of a matrix and a reinforcement of two stages. The matrix binds up the reinforcements, which increases the composite strength [Sapuan et al. 2020]. High performance composites are frequently utilised in the production of carbon fibre. The strong interface connection between carbon fibre and matrix gives the carbon fibre outstanding mechanical characteristics. The link between polymer matrix and carbon fibre thus plays a major role in stress transmission, which affects critical design parameters like strength, rigidity and weight [Dong et al. 2017]. The application of carbon 
fiber reinforced composite play a vital role in aerospace and defece sectors due to their high specific strength, impact resistance and specific rigidity. [Meng et al. 2020]. The comparison of strength of Carbon Fibre Reinforced Plastic (CFRP) in the hybrids to the strength distribution of single, isolated carbon fibres [Manders et al. 1981]. Basalt is a natural material found in frozen lava volcanic rocks by spinning process [Saravanan D 2006], melting temperatures ranging from $1500^{\circ}$ to $1700^{\circ} \mathrm{C}$ [Fiore et al. 2015]. Basalt fibre's basic costs are dependent on raw material quality and type, manufacturing method and final product features. Since the cost depends on the composition of the raw material, the chemical and mechanical characteristics. The modulus of the basalt fibers it depends on their chemical composition and the mechanical properties are slightly greater than the glass fibers [T. Deak et al. 2009]. The difference in chemical and thermal stability can be attained by changing the composition and concentration of the constituents and it affect the good mechanical and physical characteristics [Lopresto et al. 2011]. The transverse impact characteristics of the hybrid composites has been investigated and greatly improved due to hybridization [A. Dorigato et al. 2013] In general, the current generation of basalt fibres has beneficial qualities like as acoustic proofing, great heat resistance (better than glass), superior chemical resistance, and minimal absorption of water [Sun et al. 2018]. Because of its more environmentally friendly, greener and lower cost, basalt is seen as a basalt fibre because its similar mechanical characteristics and broader availability are regarded to be a fibre alternative to glass fibres. The interference between BFRP is better than the GFRP with reference to mechanical performance. [Mingchao et al. 2008]. The low ductility of carbon fibre can be improved by mixing carbon fibre with other fibres with high elongation. Based on its outstanding physical and mechanical characteristics, basalt fibre attracted increasing interest. It is also observed that the contact between basalt fibre and epoxy is better than that between fibre and epoxy resin. The tensile properties at higher temperatures is also studied in the hybrid composites [Hawileh et al. 
2016]. The interlaminar shear strength of the hybrid composites carbon/basalt / flax fibers is limited difference when compare to impact strength [E. Nisini et al. 2017]. Czigány et al. 2005 also observed that the mechanical characteristics of basalt fibres were equivalent to glass fibres, and that because of the simplification of the manufacturing method, the cost of making basalt fibres was only half that of glass fibers. The high velocity impact damage of the hybrid composite carbon and basalt laminate is increased [Tirillò, $\mathrm{J}$ et al 2017]. Hybridization of basaltic fibres with carbon fibre is consequently expected to reduce the final product costs as well as mechanical efficiency compared to pure carbon composite. The dynamic behaviour of the hybrid composites with the syntheticfibers and thermoset matrix is investigated [Shisheven et al.2019]. The cost is therefore expected to be reduced. The effect of defect zone of the hybrid composite due to drilling has studied [Subagia, I et al 2020]. [ Yang, M et al. 2018] investigated the mixing laws, models on fracture mechanics and stochastic critical model in order to calculate the mechanical properties of hybrid composites. There will be increase in mechanical performance of the hybrid composites as around $23.4 \%$ increase in energy absorption [Sajid et al. 2021].

In this paper, the interplay hybrid composites of carbon and basalt fibres as reinforcement and epoxy resin as matrix are to be prepared by compression moulding. The influence of fiber factors such as orientation, shape, material, and length on the mechanical properties of the composite will be investigated. The main focus of this paper is to characterize the overall mechanical properties based on stacking sequence of fabric layers of the hybrid composite.

\section{Materials \& Methodology}

The present research work focuses on the fabrication of hybrid composites by using Basalt and carbon fiber with epoxy resin as a matrix. Carbon and Basalt fibers are procured from local vendors. The reinforcements are stacked in such a way that it forms a hybrid laminate 
structures as shown in Fig. 1. Followed by, the Table 1 represents the sequence of laminates from CB1 to CB5.

Table 1. Stacking Sequence of Hybrid Composite

\begin{tabular}{|c|c|c|}
\hline Name & Stack and Sequence & Density $\mathbf{( K g / \mathbf { m } ^ { 3 } )}$ \\
\hline CB1 & C1, B2, B3, C4 & 1650 \\
\hline CB2 & B1, C2, C3, B4 & 1750 \\
\hline CB3 & B1, C2, B3, C4 & 1572 \\
\hline CB4 & C1, B2, C3, B4 & 1579 \\
\hline CB5 & B1, B2, C3, C4 & 1620 \\
\hline C & C1, C2, C3, C4 & 1182 \\
\hline B & B1, B2, B3, B4 & 1320 \\
\hline
\end{tabular}
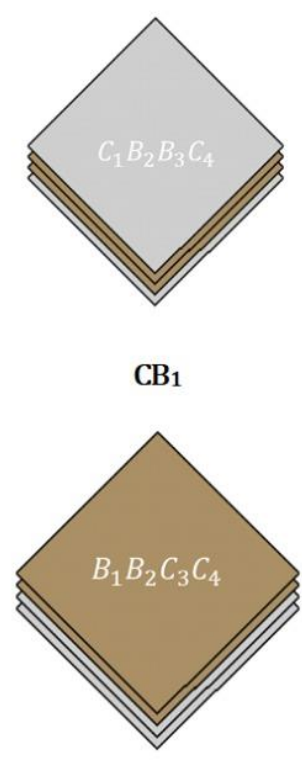

CB5

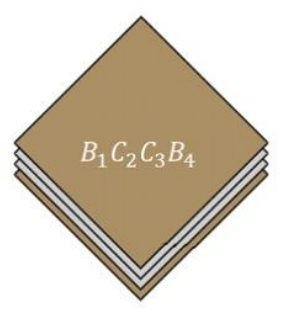

$\mathrm{CB}_{2}$

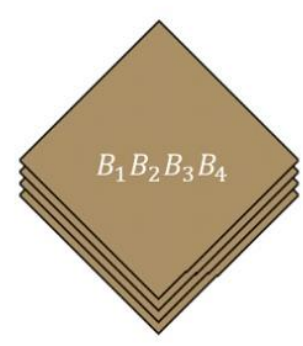

B

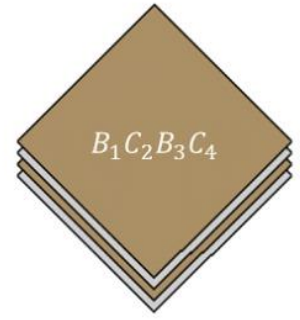

$\mathrm{CB} 3$

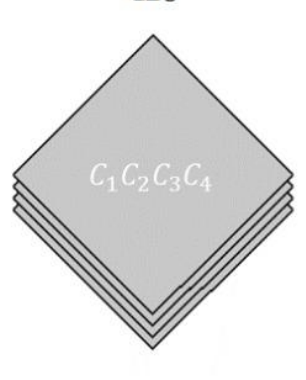

C

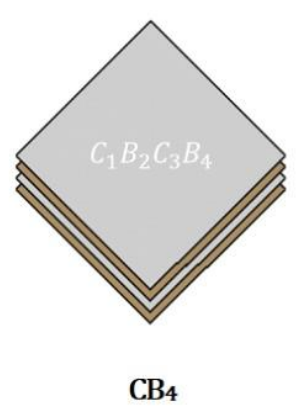

Figure1.Stacking sequence of Carbon and Basalt fibers 


\section{Methodology}

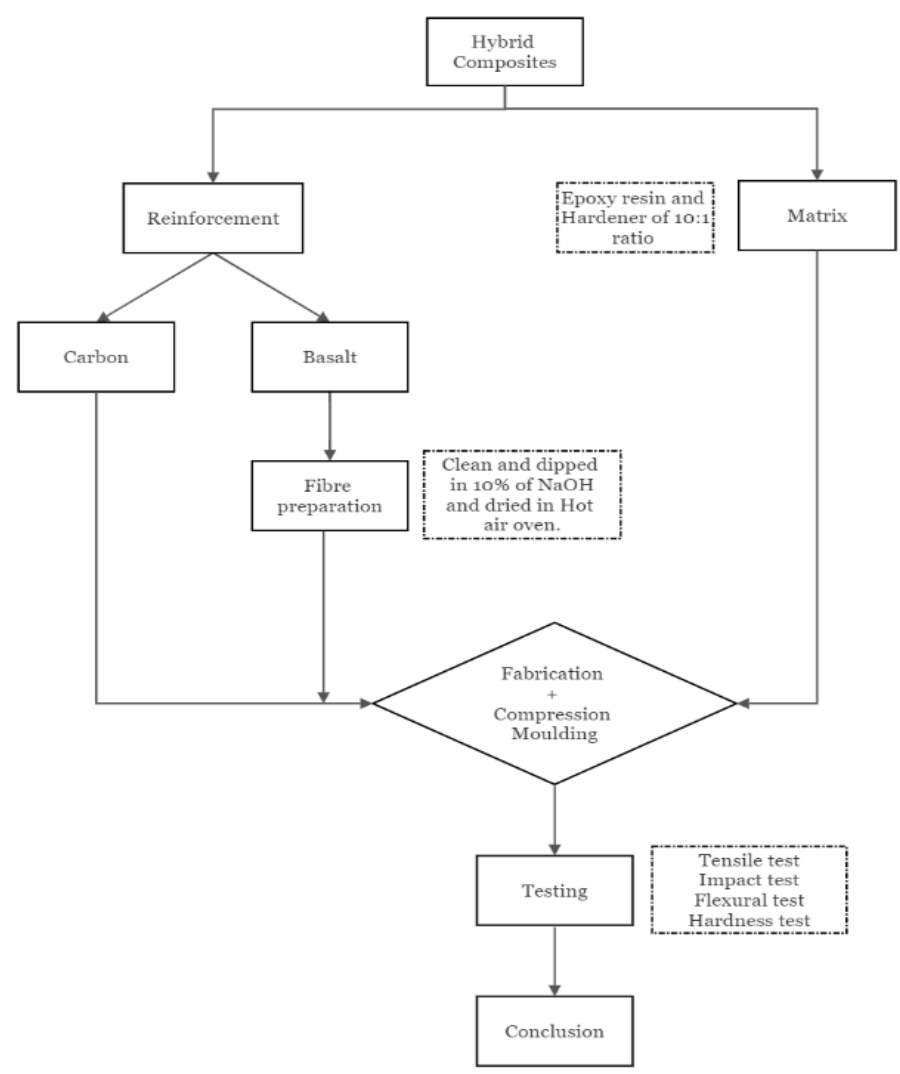

Figure 2. Process flowchart

\section{Fabrication of Hybrid Composite}

The composite fabrication process is illustrated in Figure 2 as a flow chart. For preparing the hybrid laminates, first the basalt fibres are cleaned by dipping into $10 \%$ of $\mathrm{NaOH}$ solution and dried in hot air oven. Epoxy resin with hardener is prepared as a matrix phase. The hand layup and compression moulding technique are used to manufacture the hybrid composites. Epoxy LY556 resin, and this LY556 based carbon-basalt fibre is chemically related to the "epoxide" family are used as matrix in this research work. The common name is bisphenol A Diglyceryl Ether. This is then mixed with the corresponding hardener (HY951) and epoxy resin (Araldite LY 556). Figure 3 represents the moulding die to fabricate the hybrid composites. The mould is closed with the top force or plug-in, and the material is pressurized to contact all the moulding areas, while the heat and pressure are kept constant until the moulding material heals. This experimental procedure has been maintained for 60 minutes with 250 Pascal to 
achieve better composites.

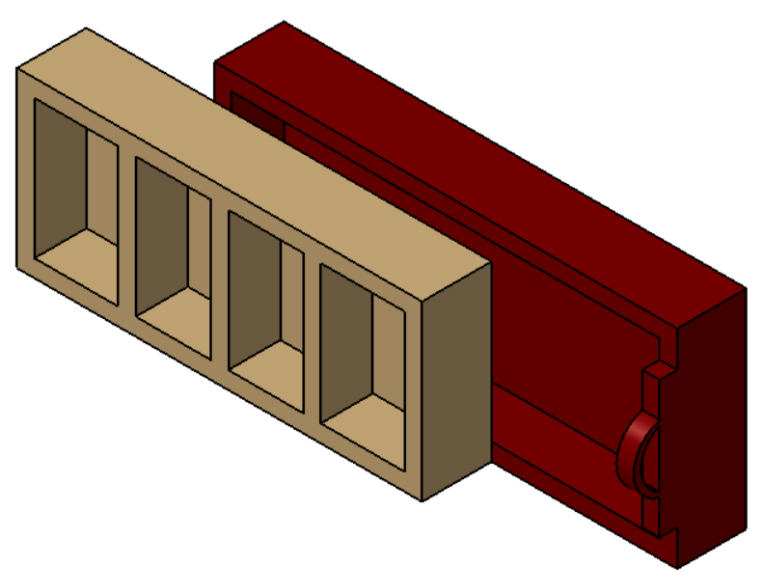

Figure 3. Moulding Die

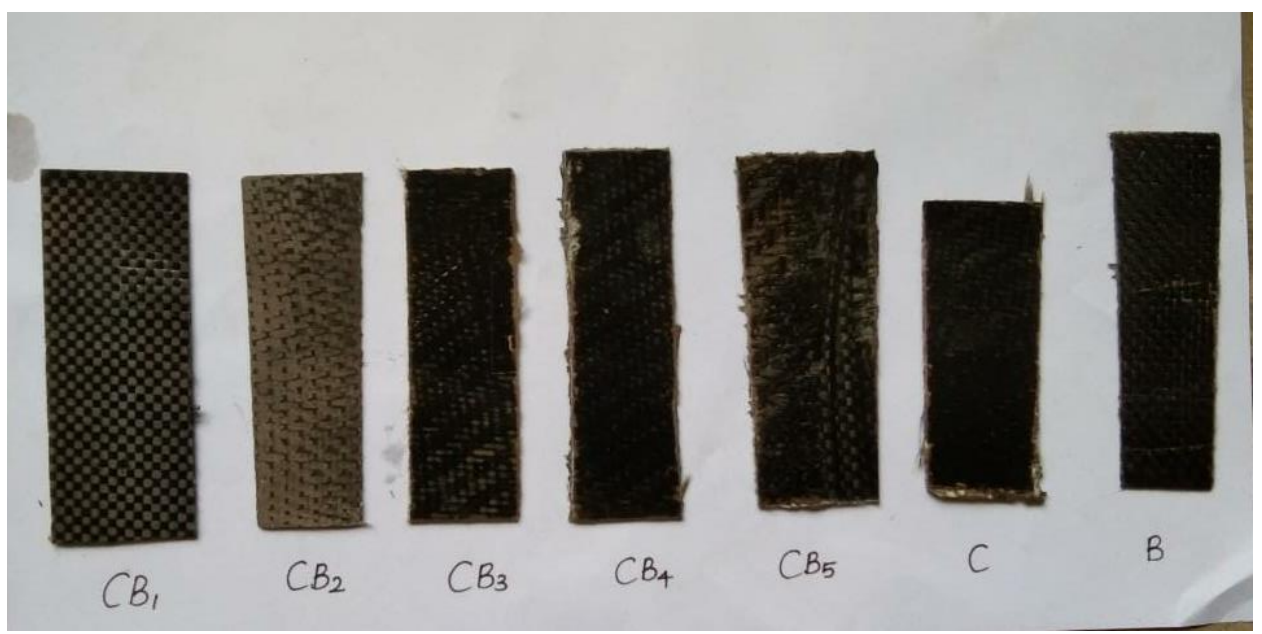

Figure 4. Fabricated Hybrid Composites

There have been seven different sample types fabricated for the present work (figure 4). The basalt and carbon fibre are cut into small pieces for easy stacking Each specimen is composed of $30 \%$ fibre and $70 \%$ resin. The mixture is manually stirred to mix the fibres in the matrix thoroughly. Each composite cast is cured for 1 hour with a load of about $25 \mathrm{~kg}$ before it is removed from the mould.

It is then cured in the air for another 24 hours after extracting from mould. Once it is fabricated, the composites are post machined and prepared as specimens for various mechanical characterizations such as hardness test, impact test, tensile and flexural test. The experimental results of each test are elaborated with graphical representation. 


\section{Result and discussion}

\section{Flexural test}

The prepared specimens are then used for testing various mechanical properties like strength, stiffness and flexural behaviour. The flexural strength of the hybrid composite specimen is evaluated through a flexural test as per ASTM D970 standard. Test results of loadvs displacement curve (Figure 5) revealed that the carbon fiber reinforced as inner layers of composite provides higher flexural strength than the other hybrid samples. However, it provides the less deformation which may lead to a brittle characteristic [ Farzin AzimpourShishevan et al. 2020]. Inclusion of basalt composites as outer fiber provides ductile behaviour at lower loads with higher displacement. This confirms that having basalt fiber with carbon fibre improves the ductility of hybrid composites upto $50 \%$, and this can be seen in the cases of $\mathrm{CB} 2$ \& $\mathrm{CB} 3$ in Figure 6.It is found during the test that the carbon fibers have low strength which fails first in the composites due to the stress concentration that leads to cracking [G.A. Subagia et al, 2013]. However, presence of basalt fibers in between the carbon fiber prevents the propagation of crack in the composites.

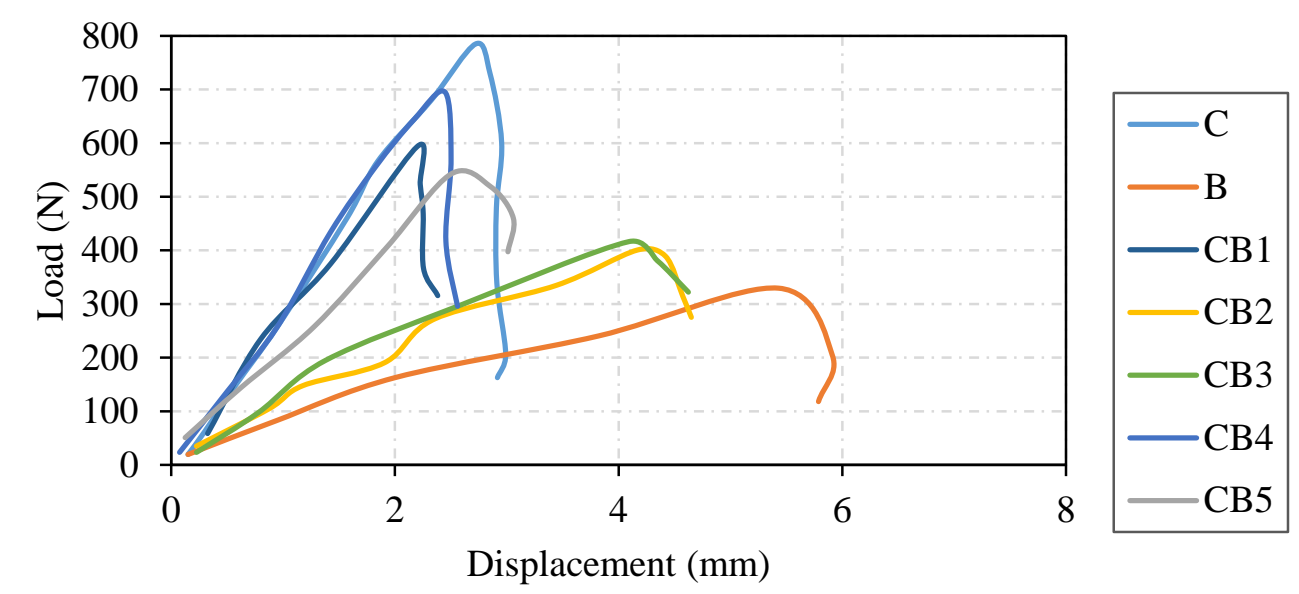

Figure 5. Load- Displacement Curve of flexural test 


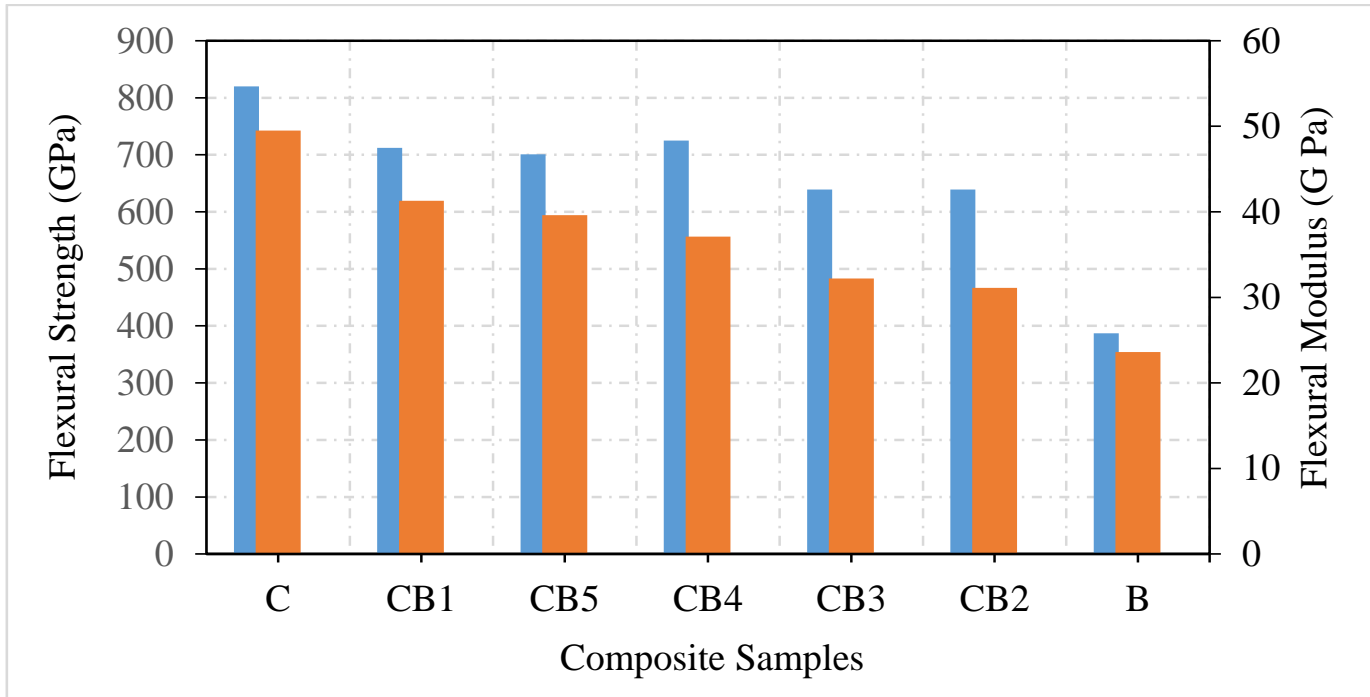

Figure 6. Flexural strength and flexural modules

\section{Impact test}

The amount of energy that the composite can absorb during collision is assessed by impact testing as per ASTM A370 standard. The specimen was reduced to $55 \mathrm{x} 25 \mathrm{~mm}$ for the impact test, and the test specimen was kept in the holder, the pendulum is suddenly released force from a known height and hitting the specimen. It is observed from the Figure 7 that the material which showed an abrupt shocking load and cause deformation or fracturing. The value was taken into perpendicular orientation to achieve a better impact resistance result. The results of impact test revealed that almost all the variety of hybrid composite offered $2 \mathrm{~J}$ of impact strength which is nearly 50\% lesser than pure basalt fiber and 50\% higher than pure carbon fiber reinforced composites. It is inferred that inclusion of carbon fibres with basalt fiber improves the impact strength of the composite by $50 \%$.

\section{Hardness test}

Hardness is measured by measuring the permanent depth or scratch of the indentation and is a resistance to indentation. In simple words, smaller the indentation against the applied force/load by the indenter, harder the material. 


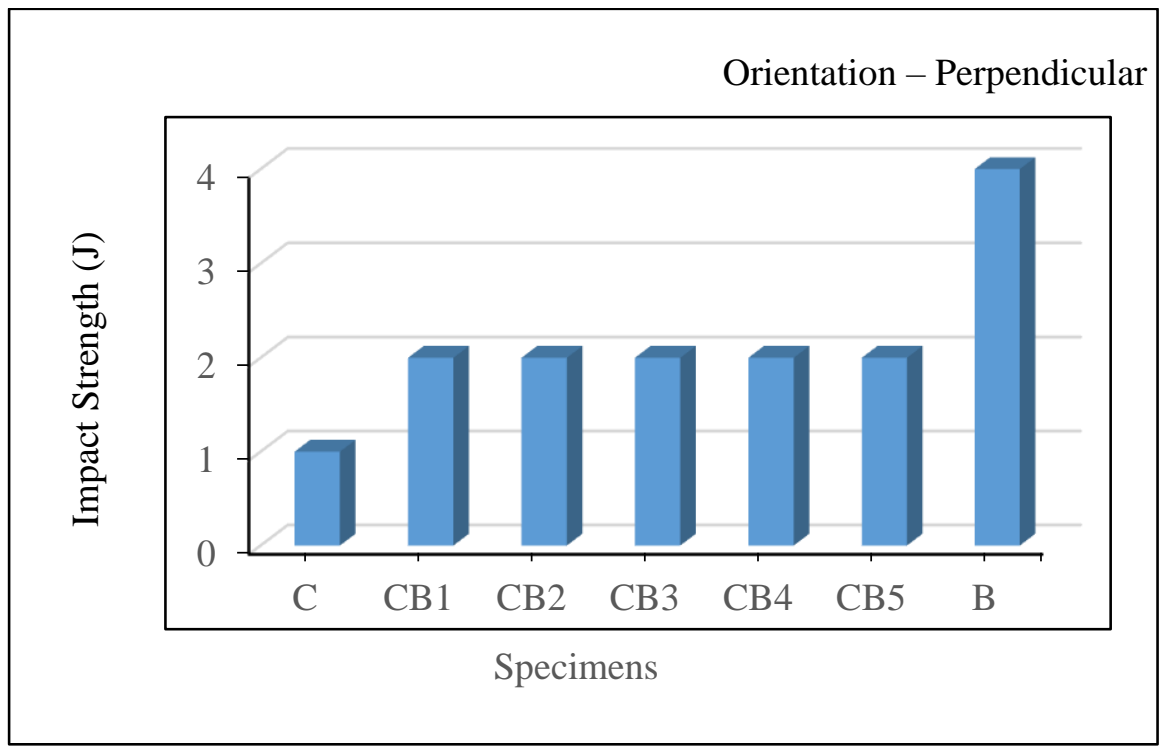

Figure 7. Impact test results.

The depth of an indentation is used to determine its hardness refer Figure 8. Here, the diameter of the ball indenter is $25 \mathrm{~mm}$ and applied force in $\mathrm{kgf}$ is 100 (Figure 8). From Figure 9, it is evident that the measured hardness of composite sequences viz. CB2 and CB3 is found low compared to other combinations. It is understood that having moderate hardness i.e. 70 HRC, CB2 and CB3 offer more flexural strength.

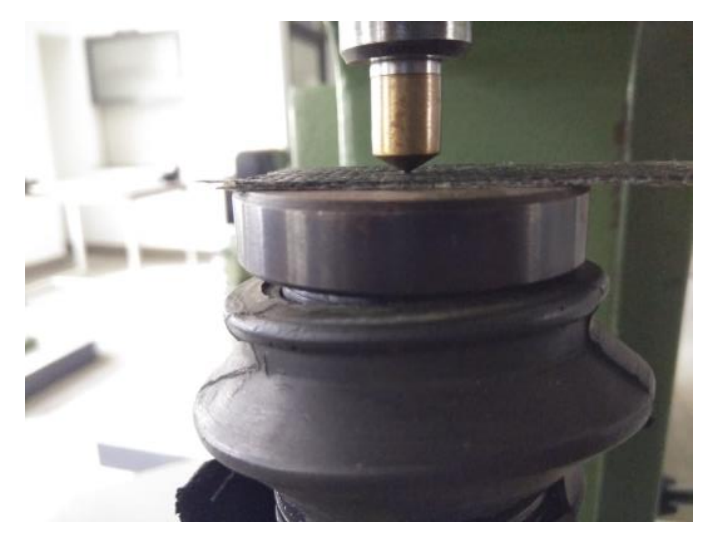

Figure 8. Hardness Test 


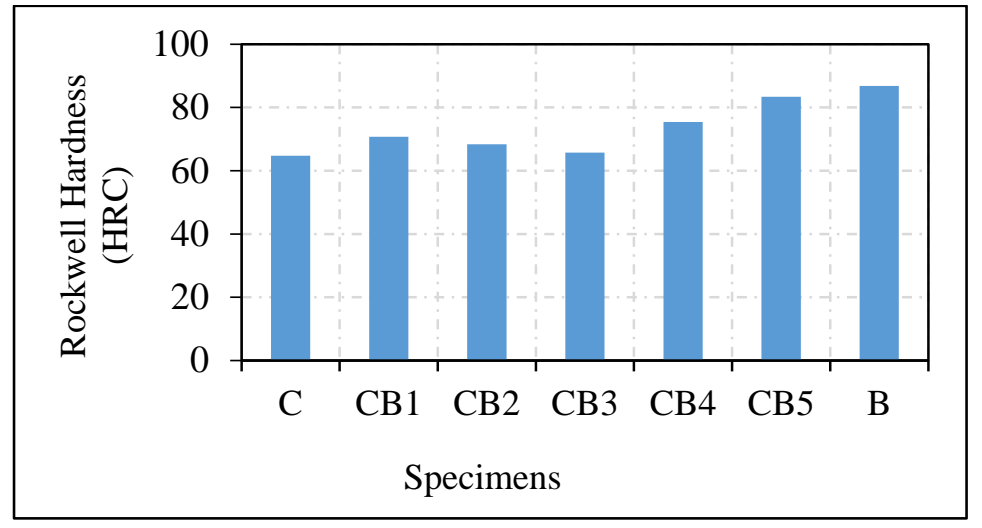

Figure 9. Hardness test results

\section{Tensile test}

Tensile strength of fabricated specimens is found by performing tensile tests as per ASTM 638 standard using the UTM machine as shown in Figure 10. The Figure 11 represents the stress strain curves, and it is noticed that the behaviour of each composite is linear in nature. It is also noticed that the presence of carbon fiber in hybrid composites provides better tensile strength when compare to basalt fiber laminate. With reference to stacking sequence, the slope of the curve varies, and CB2 and CB3 combination found to have improved tensile strength with better strain rate. It is purely due to the addition of carbon fiber with the basalt fiber.

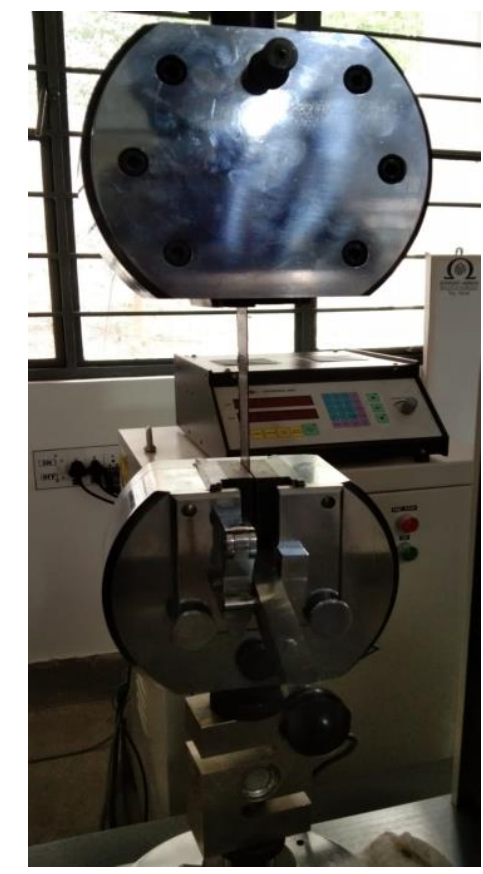

Figure 10. Tensile test 


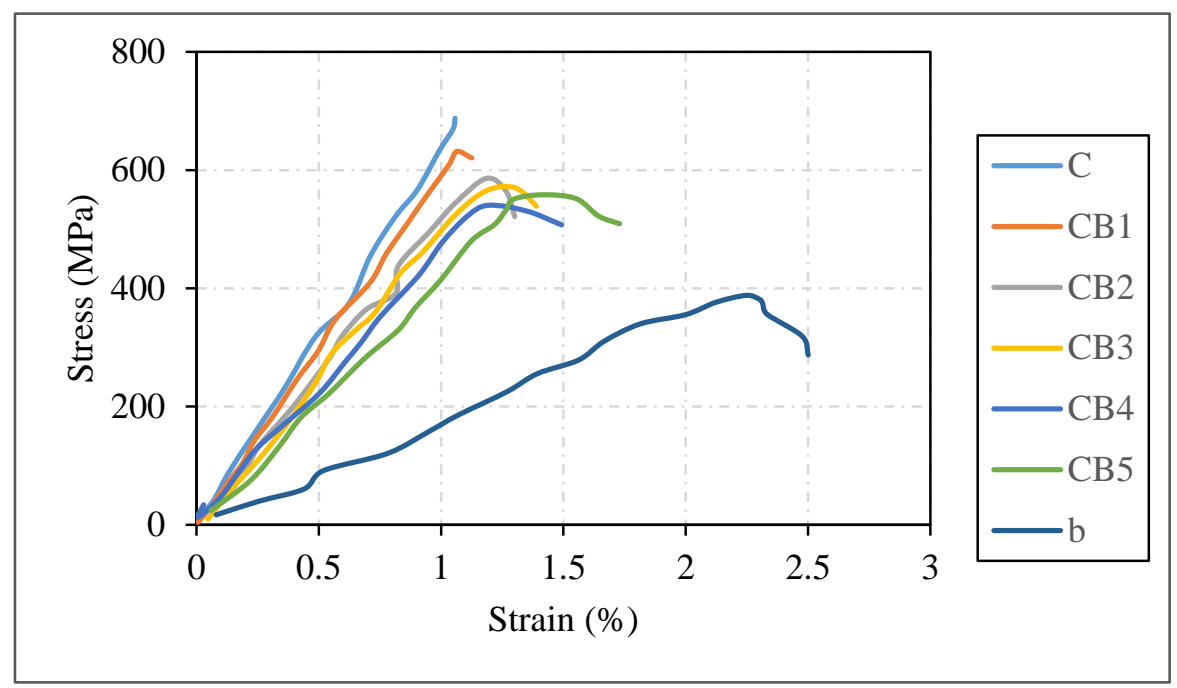

Figure 11. Stress-Strain Curve of Tensile test

\section{Conclusions}

The fabricated hybrid composites with carbon and basalt fibres as reinforcement with epoxy resin as matrix by compression moulding technique. Various stacking sequences are followed in fabricating the composites to test its mechanical properties. The following conclusions are drawn based on the test results.

- Inclusion of carbon fibres as inner layers of hybrid composite surrounded with basalt fibres offer more ductile behaviour that ensures $50 \%$ improved flexural strength.

- Higher load capability and modulus can be achieved if carbon fabric is placed as outer layer of the hybrid composites.

- The basalt enclosed carbon composites provide better toughness when compare to other composites.

- From the hardness test, it is found that the basalt enclosed carbon composites record moderate hardness that gives improved ductility to the composite.

- From the tensile test, it is noticed that the presence of carbon fiber in hybrid composites provides better tensile strength when compare to basalt fiber laminate. The 
CB2 and CB3 combination found to have improved tensile strength with better strain rate.

- From this research it is concluded that the stacking sequence of carbon and basalt fiber highly influences the mechanical properties of the hybrid fibre composites.

\section{REFERENCES}

Sapuan, S.M., Aulia, H.S., Ilyas, R.A., Atiqah, A., Dele-Afolabi, T.T., Nurazzi, M.N., Supian, A.B.M. and Atikah, M.S.N. 2020. Mechanical properties of longitudinal basalt/woven-glass-fiber-reinforced unsaturated polyester-resin hybrid composites. Polymers. 12(10): 2211 (1-14).

Dong, J., Jia, C., Wang, M., Fang, X., Wei, H., Xie, H., Zhang, T., He, J., Jiang, Z. and Huang, Y. 2017. Improved mechanical properties of carbon fiber-reinforced epoxy composites by growing carbon black on the carbon fiber surface. Composites Science and Technology. 149: 75-80.

Meng, J., Wang, Y., Yang, H., Wang, P., Lei, Q., Shi, H., Lei, H. and Fang, D. 2020. Mechanical properties and internal micro defects evolution of carbon fiber reinforced polymer composites: Cryogenic temperature and thermocycling effects. Composites Science and Technology. 191: 108083

Manders, P.W. and Bader, M.G. 1981. The strength of hybrid glass/carbon fibre composites. Journal of materials science. 16(8): 2246-2256.

Fiore, V., Scalici, T., Di Bella, G. and Valenza, A. 2015. A review on basalt fibre and its composites. Composites Part B: Engineering. 74: 74-94.

Lopresto, V., Leone, C. and De Iorio, I., 2011. Mechanical characterisation of basalt fibre reinforced plastic. Composites Part B: Engineering. 42(4). 717-723.

Sun, G., Tong, S., Chen, D., Gong, Z. and Li, Q., 2018. Mechanical properties of hybrid composites reinforced by carbon and basalt fibers. International Journal of Mechanical Sciences. 148. 636-651.

Mingchao, W., Zuoguang, Z., Yubin, L., Min, L. and Zhijie, S., 2008. Chemical durability and mechanical properties of alkali-proof basalt fiber and its reinforced epoxy composites. Journal of Reinforced Plastics and Composites. 27(4): 393-407.

Czigány, T., Vad, J. and Pölöskei, K., 2005. Basalt fiber as a reinforcement of polymer composites. Periodica Polytechnica Mechanical Engineering. 49(1): 3-14.

Sajid, Z., Karuppanan, S., Kee, K.E., Sallih, N. and Shah, S.Z.H., 2021. Carbon/basalt hybrid composite bolted joint for improved bearing performance and cost efficiency. Composite Structures. 275: 114427.

Tirillò, J.; Ferrante, L.; Sarasini, F.; Lampani, L.; Barbero, E.; Sánchez-Sáez, S.; Valente, T.; Gaudenzi, P 2017. High velocity impact behaviour of hybrid basaltcarbon/epoxy composites. Composite Structures. 168: 305-312.

Saravanan, D. 2006. Spinning the rocks-basalt fibres. Journal of the Institution of Engineers 
(India), Part TX: Textile Engineering Division 86: 39-45.

Deak, T.; Czigany, T. 2009. Chemical composition and mechanical properties of basalt and glass fibers: A comparison. Textile Research Journal. 79: 645-651.

Dorigato, A., \& Pegoretti, A. 2014. Flexural and impact behaviour of carbon/basalt fibers hybrid laminates. Journal of Composite Materials. 48(9): 1121-1130.

Subagia, I. A., \& Kim, Y. 2013. A study on flexural properties of carbon-basalt/epoxy hybrid composites. Journal of Mechanical Science and Technology. 27(4): 987-992.

Hawileh, R. A., Abdalla, J. A., Hasan, S. S., Ziyada, M. B., \& Abu-Obeidah, A. 2016. Models for predicting elastic modulus and tensile strength of carbon, basalt and hybrid carbon-basalt FRP laminates at elevated temperatures. Construction and building materials. 114: 364-373.

Nisini, E., Santulli, C., \& Liverani, A. 2017. Mechanical and impact characterization of hybrid composite laminates with carbon, basalt and flax fibres. Composites Part B: Engineering. 127: 92-99.

Shishevan, F. A., \& Akbulut, H. 2019. Low-velocity impact behavior of carbon/basalt fiberreinforced intra-ply hybrid composites. Iranian Journal of Science and Technology, Transactions of Mechanical Engineering. 43(1): 225-234.

Ma, F., Yang, M., Pu, Y., \& Zhi, Y. 2018. Response of carbon-basalt hybrid fiber reinforcement polymer under flexural load. Materials Research Express. 5(8): 085602.

Azimpour-Shishevan, F., Akbulut, H., \& Mohtadi-Bonab, M. A. 2020. Mechanical and Thermal Properties of Carbon/Basalt Intra-ply Hybrid Composites. I. Effect of Intra-ply Hybridization. Fibers and Polymers. 21(11): 2579-2589.

Subagia, I., Sutantra, N., \&Yuwono, A. H. 2020. Delamination Damages of Drilling Epoxy/Carbon/Basalt Fiber Reinforced Hybrid Composites Using Conventional Drill Machine. In Materials Science Forum Trans Tech Publications Ltd. Vol. 1000, pp.151-159. 